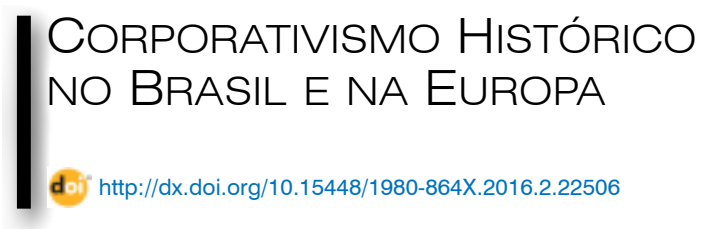

\title{
O corporativismo na História e nas Ciências Sociais - uma reflexão crítica partindo do caso português
}

\author{
The corporatism in History and Social Sciences \\ - a critical reflection from the Portuguese case \\ El corporativismo en la Historia y las Ciencias Sociales
- una reflexión crítica a partir del caso portugués
}

Álvaro Garrido*

\begin{abstract}
Resumo: Este artigo, ostensivamente teórico, procura uma reflexão crítica sobre as hermenêuticas do corporativismo enquanto fenômeno social dotado de espessura histórica. O debate mobiliza a vasta bibliografia produzida pelas Ciências Sociais a propósito do fenômeno corporativo. Entre os denominadores comuns dessa literatura salienta-se a desvalorização da historicidade das ideias e instituições corporativistas na sua ligação umbilical aos fascismos. Recuperando essa íntima relação, interpretam-se historicamente os principais significados do movimento corporativista da Europa do entre-guerras. Ancorados no lastro histórico dos corporativismos fascistas, propõe-se alguns desafios de interpretação sobre a experiência portuguesa do Estado Novo, cuja longevidade e alto grau de institucionalização sempre despertaram o interesse de historiadores e de outros cientistas sociais.
\end{abstract}

Palavras chave: corporativismo; História; Ciências Sociais; Portugal; Estado Novo

Abstract: The present paper, ostentatiously theoretic, seeks a critical reflection about the hermeneutics of corporatism as a social phenomenon possessing historic depth. The debate mobilizes the vast bibliography produced by the Social Sciences about the corporatist phenomenon. Between the common denominators of such bibliography, the devaluation of the corporatist ideas' and institutions' historicity in their umbilical connection with the fascisms is highlighted. Recuperating that intimate relation, the interwar European corporatist movement's central meanings are interpreted historically. Anchored in the fascist corporatisms' historical ballast, some challenges are proposed

* Professor com agregação na Faculdade de Economia da Universidade de Coimbra.<agarrido@ fe.uc.pt $><$ dados biográficos/ biographic data $>$ 
about the Portuguese experience of the Estado Novo - its longevity and high degree of institutionalization has always aroused the interest of historians and other social scientists.

Keywords: corporatism; History; Social Sciences; Portugal; Estado Novo

Resumen: Este artículo, ostensiblemente teórico, busca una reflexión crítica sobre la hermenéutica del corporativismo como un fenómeno social dotado de densidad histórica. El debate moviliza a la vasta bibliografía producida por las Ciencias Sociales sobre el tema del fenómeno corporativo. Entre los denominadores comunes de esta literatura sobresale-se la devaluación de la historicidad de las ideas e instituciones corporativistas en su conexión umbilical con el fascismo. La recuperación de esta relación íntima, interpretan-se históricamente los principales significados del movimiento corporativista en Europa entre las dos guerras. Anclado en el lastre histórico de corporativismo fascista, propone-se algunas dificultades de interpretación de la experiencia portuguesa del Estado Novo, cuya longevidad y alto grado de institucionalización siempre despertado el interés de los historiadores y otros científicos sociales.

Palabras clave: corporativismo; Historia; Ciencias Sociales; Portugal; Estado Novo

\section{Corporativismo e corporativismos}

A revitalização teórica do corporativismo é uma dinâmica recente, muito embebida na epistéme das Ciências Sociais. Releva o modo como essa gramática comum recobre grandes temas da memória das sociedades, propondo abordagens que tendem a dispensar a categoria da historicidade.

Neste amplo mapa de conhecimento, avultam a Ciência Política, a Sociologia e a Economia. De formas distintas, mas convergindo numa perspectiva neo-institucionalista e no uso de alguns pressupostos da teoria crítica, essas ciências do social têm promovido um retorno ao estudo do corporativismo enquanto "fenômeno total". Nas Ciências Políticas, a bibliografia norte-americana sobre o corporativismo é muito abundante, fecunda, mas por vezes repetitiva. Em geral, os politólogos e sociólogos que se ocupam do tema detêm-se na teoria e ação dos grupos de interesse, na questão dos corpos sociais intermédios e nas formas de articulação entre o Estado e a "sociedade civil". O ponto

\footnotetext{
${ }^{1}$ Para um balanço bibliográfico e sobre as perspectivas analíticas do corporativismo na "literatura internacional", vide Steven L. Kaplan; Philippe Minard (dir.), La France, malade du corporatisme? XVIIIe-XXe siècles, Paris, Éditions Belin, 2004, p. 7-12. Incidindo no caso italiano, esse balanço historiográfico também se encontra nas seguintes obras: Alessio Gagliardi, Il corporativismo fascista, Editori Laterza, Roma-Bari, 2010; Gianpasquale Santomassimo, La terza via fascista. Il mito del corporativismo, Roma, Carocci, 2006.
} 
mais saliente e comum desta produção teórica reside na desvalorização do corporativismo enquanto fenômeno histórico.

Conceito eminentemente histórico, no final do século XX o corporativismo parecia eternamente sepultado na sua própria historicidade. Referimo-nos ao compromisso íntimo e sistêmico que o ideário corporativista estabeleceu com os fascismos $^{2}$ da Europa de entre as guerras. Tal evidência parecia suficiente para prescrever o assunto e condená-lo a um relicário de ideias nefastas.

Em 1974, num artigo célebre pela sua provocação intelectual, Philippe Schmitter acordou um demônio que, ainda assim, demorou a erguer-se. "Still the century of Corporatism?", um talentoso artigo publicado e republicado por esses anos, não era apenas uma pergunta retórica destinada a romper todo um programa de investigação, mas um modo de inquirir a natureza transversal do corporativismo.

Conhecedor das experiências corporativistas sul-americanas e estudioso do "fóssil corporativista português", como lhe chamou, o sociólogo norte-americano pretendia promover a ligação entre dois tempos e dois conceitos de um mesmo fenômeno: respectivamente, o "corporativismo histórico autoritário" da primeira metade do século XX e o "neocorporativismo", ou "corporativismo democrático" da segunda metade do mesmo século, de longe o mais estudado nas Ciências Sociais desde 1970 (CARDOSO; MENDONÇA, 2012, p. 16). Buscando uma releitura do corporativismo enquanto fato social e político, Schmitter empreendeu os primeiros esforços de sistematização conceitual do tema e converteu-o, até hoje, numa matéria central da Ciência Política.

Des-historicizando o tema e as problemáticas que ele encerra, múltiplos autores têm verberado a incômoda ligação do corporativismo aos fascismos, por redutora e superficial. O próprio Philippe Schmitter (1974 e 1979), o norte-americano Howard Wiarda (1977), cujo estudo sobre o sistema português também beneficiou do seu contato direto com as instituições marcelistas, bem como, noutro plano, Peter Hall e David Soskice (2003) e ainda Colin Crouch \& Wolfgang Streeck (2006), invocam a aliança histórica entre ambos os fenômenos como "memória negra" do corporativismo. Com maior contundência de argumentos, essa sombria conjugação do corporativismo com os fascismos tem

\footnotetext{
${ }^{2}$ Por adesão teórica e reconhecimento das vantagens operativas do conceito, fazemos uso de uma definição de fascismo que recobre nesta mesma designação os regimes autoritários e totalitários que foram comuns na Europa de entre as guerras, incluindo o Estado Novo português (19331974). Nesta perspetiva, ver Pierre Milza, Les Fascismes, Paris, Éditions du Seuil, 2001; Stanley Payne, A History of Fascism, Madison, The University of Wisconsin Press, 1996.
} 
sido declarada o fator mais poluente da indispensável pluralização do conceito.

Num registo neo-institucionalista, a afirmação da pluralidade e plasticidade do corporativismo é apresentada como testemunho da diversidade institucional das "economias capitalistas avançadas" e da própria democracia. A abordagem teórica proposta para o estudo do corporativismo reside assim na análise das suas "vantagens institucionais comparativas". Por fim, este rebuscado conceito remete para a construção de índices de corporativização de uma dada economia ou sociedade: taxas de sindicalização, níveis de participação na tomada de decisões, frequência de greves, entre outros indicadores (CARDOSO e MENDONÇA, 2012, p. 6-7).

Na pegada de Schmitter, vários autores esforçaram-se por estabelecer taxonomias das diferentes formas políticas de regulação social, classificando-as conforme os referidos "graus de corporativização".

Esta perspectiva analítica conflui no debate sobre a presença de traços corporativistas na organização institucional das economias no sentido de as arrumar em tipologias assim enunciadas: "economias liberais de mercado", "economias de mercado coordenadas". Por fim, tais classificações supõem a aceitação de características corporativas que, embora vagas, a exemplo da "concorrência justa", da "eficiência do mercado de trabalho", da prevalência de modelos de corporate governance e de elevada densidade associativa dos atores sociais, são considerados valores positivos e parte intrínseca do corporativismo moderno, desde que contribuam para a otimização do mercado e para o crescimento econômico sustentável.

\section{O neocorporativismo}

Nesta distinção geral de tempos e conceitos, acresce o neocorporativismo, modelo que surgiu articulado com as democracias sociais do segundo pós-guerra e com a regulação macroeconômica de raiz keynesiana, evidenciando algumas continuidades, mas imensas diferenças, em relação à prática dos corporativismos antidemocráticos.

Esse segundo neocorporativismo, um corporativismo de associação que persiste em diversos países democráticos e que também foi designado por "corporativismo contratual" (WILLIAMSON, 1989) ou "corporativismo liberal" (LEHMBRUCH, 1979), é marcado por políticas e práticas de concertação social nas quais o Estado assume o 
papel de árbitro interveniente nas relações entre o capital e o trabalho, no sentido de alcançar uma paz social negociada, assente no Direito.

Ao Estado social de Direito democrático, que se enraizou em diversos países no segundo após-guerra, opunha-se a herança do Estado social de Direito corporativo, que em Portugal se manteve até 1974 e que Marcello Caetano teorizou, desde os anos trinta, como versão de um Estado fascista (TORGAL, 2009, p. 615-673). Quando comparado com o corporativismo dogmático e de Estado que foi constituinte dos fascismos, o neocorporativismo da segunda metade do século limitase aos domínios econômico e social e não se lhe nota a pretensão de oferecer às sociedades um novo modelo de representação política.

Durante as últimas décadas do século XX, as expressões mais acérrimas de anticorporativismo vieram da ideologia neoliberal, que começou por se expressar na Grã-Bretanha de Margaret Tatcher. Nesse contexto político, o corporativismo foi invocado e combatido num sentido amplo e considerado atentatório do regular funcionamento do mercado. Indistintamente, foram apodadas de "corporativismo" ou de "neocorporativismo" as práticas concertadas de rendas e preços, a negociação coletiva e a ação dos sindicatos em geral (CAPDEVIELLE, 2001, p. 11-33; COTTA, 2008, p. 4-36).

Hoje, o centro do debate teórico da Ciência Política interessada no fenômeno do corporativismo situa-se no estudo das formas de conciliação entre as práticas de concertação corporativistas e a otimização dos agentes no âmbito do mercado, num quadro neoliberal de Economia Política. Não por acaso, inúmeros artigos publicados recentemente em revistas da especialidade procuram tipificar as relações institucionais e fácticas entre grupos de interesse e agentes econômicos e apurar em que medida essas experiências favorecem o desenvolvimento econômico (CARDOSO e MENDONÇA, 2012, p. 6-17) $)^{3}$ Quando essa correlação se acha positiva, a plasticidade do corporativismo como sistema de concertação das relações sociais é advogada como instituição inerente às democracias capitalistas.

Na sociologia dos grupos de interesse, o corporativismo é identificado com o egoísmo dos grupos de pressão e de organizações enquistadas na defesa dos seus interesses privados (mesmo quando de grupo ou de classe) em vez de um "interesse geral" que, por definição, se crê anticorporativo (OFFERLÉ, 1998, p. 12-19). Nesta perspectiva, é comum argumentar-se

\footnotetext{
${ }^{3}$ Este ponto de situação da bibliografia recentemente publicada sobre o tema do corporativismo assenta numa análise quantitativa dos "outputs" das principais revistas internacionais. Neste balanço, confirma-se a progressiva irrelevância das abordagens históricas do corporativismo.
} 
que os países que conheceram sistemas corporativos estruturados num "estatismo orgânico" - leia-se reacionário e autoritário - herdaram uma irrevogável cultura corporativista (WIARDA, 2012, p. 263-276). A etiqueta corporativista também costuma ser usada como definição crítica de sistemas de relações profissionais pouco abertos e para definir modos de concertação social fortemente institucionalizados, nas quais o abrigo negocial do Estado ocupa um lugar importante (KAPLAN e MINARD, 2004, p. 5-31).

Estas e outras formas de corporativismo remanescente, vagamente sociológico, tendem a invocar os corporativismos históricos no mesmo plano dos societais; uns e outros enquanto técnicas de concertação social ou socioprofissional suscetíveis de aplicação em qualquer sistema político ou econômico.

Em sentido amplo, seguindo a definição de Schmitter, o corporativismo designa um sistema de representação de interesses cujas instituições se organizam num número limitado de categorias funcionalmente distintas e hierarquizadas, compulsórias e não concorrenciais, às quais o Estado concede o monopólio da representação em contrapartida de colaboração no exercício do controlo social e político (SCHIMITTER, 1974, p. 85-131).

Esta definição clássica de corporativismo social permite uma distinção vincada em relação ao corporativismo político. Conceito que o mesmo autor define como "um sistema de representação política, baseado numa visão orgânica-estatista da sociedade, em que as suas unidades “orgânicas" (família, poderes locais, associações e organizações profissionais e instituições de interesses) substituem o modelo eleitoral, centrado no indivíduo e na representação e legitimidade parlamentares, tornando-se o principal ou complementar órgão legislativo ou consultivo do governo" (SCHMITTER, 1974, p. 85-91).

Menos estabelecido e mais dependente da formulação dos próprios doutrinadores, é o conceito de corporativismo econômico cujo traço mais comum às anteriores categorias teóricas reside no organicismo e na oposição do homo corporativus, movido pelo interesse nacional e por valores comuns, ao homo economicus próprio do capitalismo liberal (BASTIEN e CARDOSO, 2007, p. 120-127). Trata-se, porém, de definições ou categorias analíticas que podem não resistir à prova histórica. Nesse plano, a distinção fundamental é binária: corporativismos autoritários e corporativismos democráticos.

No entanto, a bibliografia de Schmitter - muito mais historicizada e menos fantasiosa do que a de outros cientistas políticos que se 
interessaram pelos corporativismos - recuperou uma distinção essencial sobre a maneira como os regimes corporativos exerceram o poder do Estado sobre a sociedade: o "corporativismo de Estado" que imperou nos corporativismos fascistas a partir da década de vinte do século passado; e o "corporativismo societal" que, no segundo pós-guerra, começou a ser parte de inúmeras democracias liberais nas quais a institucionalização dos interesses mantinha (e mantêm) traços corporativistas, a exemplo de vários países sociais-democratas da Europa do norte.

Nos anos setenta e oitenta, a teorização de Schmitter já rompia com a teoria corporativista tradicional (a dos próprios doutrinadores, por mais ou menos teóricos que hajam sido), dado que trazia a debate as formas políticas de articulação dos interesses com o Estado. Perspectiva que, afortunadamente, acabou por ser acolhida em diversa historiografia (ROSAS, 2012; MADUREIRA, 2002).

\section{O corporativismo histórico e os seus contextos}

Embora indispensável, esta gramática geral do corporativismo teórico pode ser redutora para fins de análise histórica. Importa distinguir o corporativismo como doutrina, ou discurso ideológico das direitas autoritárias e antiliberais, do corporativismo institucionalizado, ou seja da ideia corporativa feita sistema, vertida nas suas funcionalidades políticas. A noção de corporativismo é variada e de vários tempos, mas tal não significa que possa tomar uma definição a-histórica.

A ideologia corporativa serviu para edificar um conjunto de instituições assentes na integração forçada dos interesses organizados no Estado. Apesar das formas variáveis que a ideia e os sistemas corporativos assumiram, o corporativismo foi um dos instrumentos políticos mais duráveis das ditaduras (PINTO, 2014).

Enquanto ideologia histórica assente na recusa da luta de classes e na defesa de uma cooperação harmônica dos grupos e interesses capaz de evitar a conflitualidade social, o corporativismo é uma ideia recente. Doutrina marcadamente interclassista, surgiu acossada pelos socialismos que emergiram nas sociedades industrializadas do século XIX. O corporativismo foi reinventado para promover a inibição política e social do potencial conflito entre "capital" e "trabalho". Com esse propósito concreto e reacionário, declarou-se uma alternativa de representação política autoritária à democracia liberal e ao comunismo.

A ideologia corporativa nasceu embebida na luta que se travou, na Europa do século XIX e durante as primeiras décadas do século XX, para 
que o Estado encontrasse uma resposta sistémica, anti-individualista, anticontratualista e não revolucionária para a "questão social".

Cremos que esta definição oferece a vantagem de uma maior historicidade, na medida em que remete para o fenômeno dos corporativismos históricos modernos que diversos autores designam por "corporativismos reais", numa analogia com a noção de "socialismo real".

Tal como o liberalismo, que na Europa dos anos trinta do século XX conhecia a sua primeira crise institucional cavada pela "grande depressão", nessa época as ideias corporativistas conheciam o seu segundo fôlego histórico, após um longo hiato associado à negação que delas fizera o Estado liberal, que proibira as corporações abrindo caminho ao sindicalismo de classe. Posteriormente, os Estados que se disseram corporativos proibiram os sindicatos livres para resgatar as corporações (embora outra sorte de corporações), num exaltado regresso a um passado orgânico, feito de harmonias sociais, à imagem de um corpo.

Apresentado como solução para a crise do Estado liberal e dos seus modos de representação social e política, o corporativismo inspirou a Igreja Católica Romana - instituição que primeiro o propôs como terceira via oposta ao socialismo e ao capitalismo liberal. Alimentou partidos conservadores demoliberais, animou movimentos radicais de direita e insuflou todos os movimentos e partidos fascistas, bem como as elites tecnocráticas das várias direitas que abraçaram a "alternativa do século", como the chamou Mihail Manoilesco (MANOILESCO, 1934, p. 8-32).

O catolicismo social oitocentista foi o primeiro afluente dessa gama de ideologias de "terceira via" que conheceu expressões políticas variadas. Em especial, na reação ultraconservadora da Action Française e, um pouco mais tarde, nos próprios regimes fascistas. Nos fascismosregime, variaram os modos de articular o Estado e a "sociedade civil", bem como os modelos de articulação da política com a economia. Mas a todos os fascismos foi comum a doutrina organicista que recusava a concepção universalista e republicana de "bem comum", assim como os princípios do sufrágio universal e da representação pluripartidária.

$\mathrm{Na}$ sua historicidade contemporânea, o corporativismo foi também um dispositivo político de combate à democracia parlamentar e ao sindicalismo revolucionário; um modelo de representação política anti-individualista; uma nova forma de representação dos interesses organizados que alimentou um processo de difusão transnacional das 
instituições angulares das ditaduras fascistas (PINTO, 2014, p. 20). A integração do sindicalismo no Estado é a ideia central do corporativismo enquanto doutrina e a tarefa prioritária do corporativismo enquanto regime.

\section{Para uma hermenêutica dos corporativismos históricos}

A maioria dos historiadores do corporativismo, hoje outra vez numerosos em França e persistentes em Itália e Espanha, têm distinguido assim os dois principais tempos históricos do corporativismo:

1. O corporativismo de Ancien Régime, que persistiu em diversas sociedades enquanto modelo de organização socioprofissional assente nas Corporações, instituições que o liberalismo começou por abolir e proibir em finais do século XVIII, por associadas à persistência de privilégios;

2. O "corporativismo moderno", doutrina conservadora e reacionária, que se apresentou como solução de "terceira via" para resolver a questão social aberta pelas sociedades industrializadas, rejeitando quer o individualismo liberal quer o coletivismo marxista no sentido de uma paz social compulsiva.

Nos países da Europa do sul que conheceram regimes autoritários de inspiração fascista, a palavra corporativismo tornou-se hiper-referencial do ponto de vista sociológico e sub-analisada do ponto de vista histórico. Para este desequilíbrio concorrem a excessiva pluralização teórica do conceito sociopolítico de corporativismo e apropriações ligeiras da memória dos "corporativismos históricos".

Como estudar o corporativismo? Como submeter a dogmática corporativa à análise histórica, dado que o tema se compõe de conceitos de fundo moral, de ilusões doutrinais e de um denso património de organizações cujo critério instituinte se supõe fundamentalmente político?

Fazer história do corporativismo obriga a esforços redobrados no escrutínio das autenticidades. Trata-se de um tema que carrega a sua própria lenda e por isso muito marcado pelas vicissitudes da memória histórica, que peleja por interpretações interessadas. Por muito que se invoque a plasticidade ideológica do corporativismo e se admita a pluralidade do conceito, enquanto categoria histórica ele carrega a íntima relação que manteve com os regimes fascistas.

Adaptando o silogismo de Manuel de Lucena, colhido no célebre livro de Mihaill Manoilesco, podemos dizer que se nem 
todos os corporativismos foram fascistas, todos os fascismos foram corporativistas (MANOILESCO, 1934, p. 17). Significa que a ideia corporativa e as suas instituições foram um instrumento de disciplina social e de dirigismo econômico do "fascismo genérico" que se implantou na Europa e noutras partes do mundo no tempo sombrio de entre as duas guerras mundiais.

Neste como noutros temas de investigação histórica que exigem distinguir o discurso da ação (ou a realidade das meta-realidades), há que situar a perspectiva de análise. Pretende-se pensar historicamente - o que supõe a pretensão de explicar - um tema que, dada a densidade doutrinária dos discursos que comporta e os ardis da propaganda, requer especiais cuidados analíticos.

O estudo do corporativismo autoritário europeu do século XX pede um esforço comparativo, de modo a permitir interpretações caso a caso e Estado a Estado. Um bom caminho de estudo será o de comparar entre si as diversas experiências nacionais corporativistas, considerando os usos políticos da ideia corporativa e dos aparelhos institucionais que nela se apoiaram para cumprir, entre outras, as seguintes finalidades: impedir o sindicalismo livre e potencialmente revolucionário; reorganizar a economia liberal debaixo dos interesses do Estado autoritário e das suas recompostas oligarquias; ordenar a sociedade de modo a prevenir a desordem pública e movimentos sociais hostis; impor sistemas de intermediação de interesses de forma a regular as relações entre o público e o privado no âmbito de instituições fortemente controladas pelo Estado.

Outra via de método - e outra cautela epistemológica - reside na necessidade de temperar a dogmática doutrinária e a ideologia totalizante do corporativismo com um esforço de interpretação das suas finalidades instrumentais e de compreensão das singularidades nacionais dos sistemas políticos que se reclamaram "corporativos".

A ideologia e o discurso doutrinário corporativista não pedem uma exegese, mas uma hermenêutica histórica. No essencial, importa explicar de que modo o corporativismo se fez um instrumento de disciplina social e de intervenção econômica no âmbito dos regimes que o instituíram.

Pôr em evidência o uso político e institucional do corporativismo implica tomar os sistemas corporativos como sistemas de "terceira via", fazendo fé na profecia doutrinal, de modo a captar os seus fins instrumentais. Mas também exige privilegiar analiticamente o factor organização, principal imperativo doutrinário dos corporativistas para quem a organização corporativa era uma força autônoma que, pela mão 
do Estado, acabaria por dirigir os fatores de produção e as próprias relações sociais (PEREIRA, 1937, p. 108).

Teoria, doutrina, leis, e os mais diversos documentos que evocam o quotidiano burocrático dos organismos que funcionaram no âmbito dos sistemas corporativos, compõem uma assombrosa torrente de discurso. Mesmo quando os documentos falham, por mal preservados ou porque, como sucede no caso português, a política de arquivos insensatamente não considerou as instituições corporativistas constituintes do regime deposto em 1974, estamos perante uma memória documental muito densa, que o legislador e o burocrata parecem ter gerado para exprimir a racionalidade e eficácia das próprias instituições.

Quando não se perderam nos labirintos das transições políticas e reformas do Estado, esses enormes fundos documentais de natureza institucional parecem ter sido destinados a persuadir os contemporâneos do sistema corporativo acerca das virtudes da "ideia do século" - assim chamou Manoilesco (1934) ao "corporativismo integral e puro", quando o declarou o único sistema de ideias capaz de resolver a "questão social" vinda do século XIX.

Por estática e estrutural que pareça, a "ideia corporativa" foi um campo de ensaio social e uma doutrina econômica muito debatida e controversa: proclamada e logo deturpada, essencial mas falsa, necessária porém contingente. Estudá-la nos contextos sócio-institucionais onde o corporativismo foi instituído com consentimento ou resistência significa dissecar os corporativismos-regime nas suas estruturas mais críticas, entre a ideologia e as práticas sociais, entre o dogma e as suas realidades.

No caso português, a temática do sistema corporativo foi das primeiras a contribuir para uma historiografia do Estado Novo e para o entendimento da sua arquitetura política e institucional. Em pleno marcelismo, o arranque da historiografia portuguesa referente ao corporativismo - uma coincidência que tem mais que se lhe diga e que, em certos casos, não fugiu à tendência neocorporativista que marcou as sociais-democracias do tempo - elegeu a problemática do corporativismo como prioridade. Não apenas porque boa parte das fontes históricas eram (e são) compostas por Leis, documentação relativamente fácil de reunir e consultar - assim optou Manuel de Lucena na sua mémoire de fin d'études apresentada ao Institut des Sciences Sociales du Travail de Paris, em 1971, publicada em $1976^{4}$ - e de Philippe Schmitter, que em

\footnotetext{
${ }^{4}$ Amémoire de Manuel de Lucena resultou na sua monumental monografia em dois volumes, que ainda hoje se deve considerar o estudo mais completo sobre a experiência corporativa portuguesa associada ao Estado Novo: O Sistema Corporativo Português, Lisboa, Perspectivas \& Realidades, 1976.
} 
1971 rumou a Portugal a fim de estudar, segundo o próprio sociólogo americano, "um caso de paleontologia política": o "corporativismo de Estado" português que, embora imposto na década de trinta, sobrevivera ao desfecho da Segunda Guerra Mundial e resistira à morte de Salazar, inclusivamente com promessas de reforma no âmbito do "Estado social" imaginado por Marcelo Caetano.

A análise histórica dos processos de institucionalização da teoria e doutrina corporativas continua a ser escassa e intermitente, como se tratasse de um tema bolorento ou "menor" para a historiografia do Estado Novo. Uma simples pesquisa bibliográfica evidencia um claro predomínio de estudos sobre o corporativismo enquanto sistema político e ideológico.

Mais raros são os trabalhos dedicados ao corporativismo enquanto sistema econômico e institucional de condução da vida econômica e social portuguesa, ou seja, de estatização nacional da economia e da própria sociedade. Ressalvem-se os escritos de Manuel de Lucena, em parte já citados, que conjugam a perspectiva política, jurídica e institucional e reúnem preciosas intuições interpretativas sobre outras faces do sistema corporativo português (LUCENA, 1989, p. 505-555; 1976, p. 97-206; 2010, p. 153-202).

O corporativismo instituído entre as duas guerras mundiais estabeleceu-se em claro compromisso com a natureza autoritária ou totalitária dos respectivos Estados e foi um dos seus eixos. Em certos casos, a exemplo dos fascismos italiano e português, o corporativismo tomou parte saliente nas instituições do sistema político, configurou a ideologia do Estado e definiu o modelo econômico de institucionalização da nação.

Enquanto doutrina social antidemocrática, antiliberal e antiassociativa, o corporativismo começou por ser um instrumento de eliminação do sindicalismo de classe autônomo e de destruição dos seus laços de ideologia e movimento com os socialismos revolucionários. Embora variando conforme os regimes que o adotaram como ideologia de exercício do poder do Estado sobre a sociedade, o corporativismo foi, também, um instrumento de institucionalização econômica da nação da "nação orgânica" exaltada pelos corporativistas, que a prometiam resgatar da história, reinventando uma tradição que teria sido rasurada pelos iconoclastas liberais.

Nesta ordem comum de discurso, tenham os sistemas corporativos nacionais assumido a forma político-jurídica do "corporativismo de Estado" ou o perfil de "corporativismo de associação", a ideologia 
corporativista foi uma expressão de nacionalismo instituído. Por iniciativa autoritária dos Estados, os sistemas corporativos assentaram na recusa dos valores liberais do individualismo e da concorrência, bem como na rejeição dos princípios socialistas de ação coletiva e revolução.

Enquanto ideia em movimento no contexto histórico de superação autoritária do Estado liberal, o corporativismo despertou um entusiasmo internacional evidente em inúmeras publicações, conferências e centros de estudos.

\section{Uma "internacional corporativista"?}

Quando a ideia de uma "internacional corporativista" se começou a difundir na Europa, a partir de 1929, já eram muitas as críticas à experiência italiana do corporativismo fascista. A mais célebre obra de divulgação do corporativismo moderno, nacionalista e autoritário foi publicada em França, em 1934, pelo romeno Mihail Manoilesco. O livro exprime uma visão crítica da prática corporativista que se conhecia da Itália de Mussolini, cujos desvios ao "corporativismo de associação" ocuparam obsessivamente diversos doutrinadores portugueses.

Embora não fossem propriamente anticorporativistas, os corporativistas de vários países que invocaram a tradição solidarista inspirada em Léon Bourgeois, Charles Gide e Émile Durkheim, bem como os corporativistas de esquerda que se disseram sindicalistas revolucionários recorrendo a Saint-Simon, a exemplo de Georges Sorel, Enrico Corradini e Marcel Déat, abriram fundas polêmicas entre as próprias hostes corporativistas. Estas e outras divergências impossibilitaram a construção de uma ordem corporativa internacional, cuja expressão se confinou à inconsistente "economia corporativa" (ALMODÔVAR e CARDOSO, 2005, p. 333-354).

$\mathrm{Na}$ sua decantação historicista, muito frequente na retórica corporativa e rebatida por todas as correntes anticorporativistas, o corporativismo exaltava a sua expressão medieval. O exemplo maior estaria nas corporações profissionais de ofícios ou mesteres e noutras "corporações naturais", como a família, a paróquia, os compromissos religiosos e irmandades, as universidades e as ordens militares. Também no caso português, o próprio Direito Administrativo, uma vez coligido e afeiçoado às ideias corporativistas, nomeadamente por Marcello Caetano entre 1936 e 1940, comprometeu-se com a forma corporativa do Estado, incumbindo-se de exaltar as origens orgânicas do corporativismo e de invocar uma remota tradição nacional de modo a justificar o seu carácter 
"natural" e "histórico" (CATROGA, 2014, p. 162-176; AMARO, 2012, p. 101-119).

No âmbito das ideologias de "terceira via" que conheceram diversas expressões políticas e vários modos de articulação do Estado com a economia e a sociedade, a utopia conservadora de retorno às comunidades naturais encontrou na ideia de Corporação a sua instituição total.

Contra-revolucionários, os corporativistas faziam crer que, no trabalho e na sociedade em geral, só a Corporação permitiria conjugar a obrigação moral e profissional com os fins de proteção social. Foi contra esta ordem social idílica, assente no poder e privilégios das corporações do Antigo Regime, que o liberalismo triunfante se manifestou radicalmente anticorporativo, desde logo nas leis francesas de 1791. O reformismo liberal foi desferido precisamente contra as Corporações, proibindo-as, proclamando a liberdade do trabalho e interditando qualquer forma de associação ou reivindicação coletiva.

$\mathrm{O}$ ralliement do corporativismo com o princípio autoritário e totalitário das várias direitas europeias que subscreveram a ideia de uma "terceira via", foi politicamente eficaz porque agitou todos os fantasmas que anunciaram a crise ou a derrocada do Estado liberal. Independentemente das suas diferenças ou matizes, todos os corporativistas brandiram os riscos do individualismo e materialismo. Denunciaram a anomia social identificada pelos solidaristas, o parlamentarismo estéril e a insidiosa ideia de nação inventada nas revoluções liberais. E todos pugnaram por um regresso a uma ordem social orgânica que dispensasse a luta de classes.

Agitando esses medos e vazios, ergueram-se, em primeiro lugar, o catolicismo social e a intransigência papal, em contingente aliança. $\mathrm{Na}$ década de 1870, em França e na Bélgica já se propunha um retorno à "ordem cristã", a única suscetível de assegurar a paz social, recuperando o valor moral e profissional do trabalho. Também se defendia uma ordem política de raiz tomista, assente na representação dos corpos intermédios, ideia que muito se animou no final do século. Esse sistema sociopolítico antirrevolucionário e antidemocrático não poderia funcionar sem um "Estado forte", capaz de tornar obrigatórias as corporações, embora algumas correntes corporativistas cristãs as tenham reclamado "livres". Outro debate foi travado em torno da opção por sindicatos mistos ou separados, ou seja, mais ou menos corporativos.

No final da Grande Guerra, antes da sua fusão com o Partido Fascista, nacionalistas como Alfredo Rocco e Enrico Corradini 
defenderam um "corporativismo integral" e um "sindicalismo nacional". Para o estatista Rocco, futuro ministro da justiça de Mussolini (19251932), o "corporativismo integral" significava a união dos interesses organizados no Estado, bem como a eliminação do Parlamento e do Senado em favor de corpos representativos das profissões e de outros grupos (GAGLIARDI, 2010, p. 14-15).

A reforma institucional fascista-corporativista implicou mesmo a eliminação da representatividade liberal (PINTO, 2014, p. 27-28). Embora a Carta del Lavoro, de 1927, não tenha concretizado todas as aspirações do sindicalismo fascista, foi o documento mais influente para as ditaduras que adotaram um corporativismo total, mas sobretudo social e econômico: o Portugal de Salazar, a Áustria de Dolfuss, a Espanha de Franco e a França de Vichy.

Na Itália como em Portugal, embora o corporativismo econômico tenha sido o mais saliente, ele não obedeceu a um programa claramente definido na medida em que decorreu, subordinadamente, do corporativismo social. Mesmo no fascismo italiano, o primeiro ímpeto de corporativização foi de natureza social. Embora o Ministério das Corporações tenha surgido cedo, em 1926, a corporativização do sistema político e social foi lenta e exasperou os mais puristas ou radicais. Apenas em 1936, quase quinze anos depois da tomada do poder, Mussolini decidiu criar a Câmara Fascista e das Corporações, principiando uma representação política de tipo corporativo (GAGLIARDI, 2010, p. 70-81).

Igualmente desapontados com a prática fascista e burocrática dos sistemas corporativos italiano e português ficaram os católicos sociais, embora muitos se tenham tornado bons corporativistas de Estado. A decepção, ou mesmo a dissidência, vieram daqueles que fizeram uma leitura menos integrista das encíclicas papais Rerum Novarum, de Leão XIII (1891), e Quadragesimo anno, de Pio XI, tomando-as como a base de um corporativismo social-cristão cuja ética em nada se poderia confundir com a forma secular e burocrática que vingou nos principais sistemas corporativos.

Foram exemplo dessa deriva o corporativismo fascista italiano, os regimes português e austríaco, ou mesmo a Espanha de Franco e o Brasil de Vargas. Um amplo espectro de corporativismos estatistas, autoritários e fortemente burocráticos, regimes que tiveram alguns ideólogos comuns, como os italianos Rocco, Bottai (ambos ministros de Mussolini e ambos estatistas) Spirito, e Bortolotto, juntamente com o austríaco Othmar Spann e o próprio Manoilesco, um apóstolo inconsistente do corporativismo de associação. 
A ideia de uma "economia dirigida internacional", assente na Corporação como entidade semiautônoma capaz de substituir a assolada base institucional do sistema capitalista liberal, foi também muito difundida, nomeadamente por De Michelis e pelo próprio Manoilesco.

Nos diversos países que conheceram regimes de tipo fascista, a economia dirigida que se reivindicou corporativa instituiu modelos administrativos de regulação econômica estatal. Esta contradição angular acompanhou o corporativismo econômico em todos os casos ou sistemas em que habitou a própria natureza dos regimes corporativistas e fez parte das suas lógicas de poder sobre a sociedade.

$\mathrm{O}$ corporativismo trouxe um novo fôlego à "administração reguladora indirecta". Atribuiu às suas instituições poderes de regulação econômica, mas fê-lo no âmbito do Estado ou no interposto domínio das organizações corporativas. Essas instituições surgiram com o fascismo, em Itália, a partir de 1923, e em Espanha, com a ditadura de Primo de Rivera, no mesmo ano (MOREIRA, 1997, p. 194-199). Segundo François Perroux, economista católico francês que se destacou pelos seus textos de "crítica democrática e construtiva" aos sistemas corporativistas do tempo, no caso italiano o compromisso histórico da ideia corporativa com o "estatismo fascista" - a expressão é do próprio - teve um sentido concreto: resolver o problema econômico italiano, entretanto agravado devido à política de revalorização da lira, anunciada em Agosto de 1926 (TONIOLO, 1980, p. 99-121). Perroux considerou que, ao fazer uso do corporativismo como recurso institucional e político da unidade da nação, a política econômica fascista acabou por ser uma forma de "capitalismo de Estado" (MORNATI, 2009, p. 728-729). Ao assentar no poder autoritário do Estado e numa organização corporativa não representativa, a prática do corporativismo italiano desmentiu o dogma da "economia nova"; acabou por opor soluções inadequadas à crise estrutural do capitalismo, considerou o economista francês.

A historiografia moderna sobre o fascismo italiano não desmente estas interpretações. Por efeito das dívidas de guerra, da inflação e da persistência de problemas monetários nos primórdios do regime fascista, as políticas de estabilização econômica lançadas em 1925 e a legislação social corporativa imposta no ano seguinte pelo ministro da Justiça Alfredo Rocco precipitam a transição de um "fascismo liberal" para um "corporativismo subordinado e parcial" - ostensivamente um corporativismo de Estado. Processo que resultou no reforço do intervencionismo estatal e numa economia dirigida através do Partido Nacional Fascista (ADLER, 1995, p. 347-357). 
A corporativização forçada das organizações de patrões e trabalhadores conduzida ao abrigo da Carta del Lavoro (1927) instituiu uma sindicalização assimétrica que perdurou até 1945 . Nem nas empresas, nem tão pouco nas organizações profissionais, havia qualquer representação conjunta de trabalhadores e patrões. Na prática, a Carta oferecia aos patrões o direito exclusivo de direção da atividade econômica e das empresas, remetendo a burocracia sindical para um domínio marginal e administrativo (BERNARDO, 2003, p. 246-247).

Também em Itália, a crise mundial apressou o dirigismo econômico. O seu maior impulso institucional residiu na criação do Conselho Nacional das Corporações, em 1930, cujo papel significou a coordenação das relações econômicas entre as várias categorias de produtores, a regulação das relações entre patrões e assalariados e a ação assistencial dos sindicatos profissionais (FERNANDES, 1938, p. 211-221). A organização da economia foi a partir de então ainda mais estatista e menos corporativa: assentou na criação de dezenas de cartéis e consórcios públicos de oficiosa obediência ao Partido Nacional Fascista. A lógica de organização desses cartéis foi setorial, em regra por produtos, como sucedeu no caso português que, em boa medida, seguiu a experiência italiana. Os Entes Nacionais do Arroz (1931), cuja campanha de fomento inspirou uma tímida "campanha do arroz" em Portugal, da Celulose e do Papel (1935), e o da Beterraba Sacarina (1937) são exemplos da transversalidade dos setores econômicos abrangidos pela cartelização fascista (MOREIRA, 1997, p. 215).

\section{Desafios de interpretação sobre a experiência portuguesa}

Philippe Schmitter advertiu sobre a tentação de ignorarmos o corporativismo português pelo simples fato de ele ter sido "anacrônico e irrelevante". "Se o fizéssemos", acrescenta o sociólogo americano, "estaríamos a ir ao encontro daqueles que já chegaram à conclusão de que o Estado corporativo de Mussolini não passava de uma aldrabice, bem como daqueles que insistem em levar o corporativismo a sério como se fosse um autêntico tertium genus entre o capitalismo e o socialismo" (SCHMITTER, 1999, p. 166).

Nem uma coisa nem outra. Em rigor, o corporativismo português - que sempre se anunciou "associativo" ou "autodirigido" - foi uma fraude. Primeiro, porque apenas existiu enquanto "corporativismo de Estado", conforme concluíram diversos autores e, antes deles, alguns 
doutrinadores do próprio sistema. Segundo, porque as corporações, órgãos de cúpula de um verdadeiro sistema corporativo, levaram mais de vinte anos a serem criadas e quando o foram (em 1956-57) pouco funcionaram. Por último, porque o caráter corporativo do Estado Novo, solenemente vertido na Constituição portuguesa de 1933, foi apenas uma veleidade, decerto resultante da necessidade de achar um móbil moderadamente revolucionário para o novo regime. Acresce que a Câmara Corporativa, prevista na Constituição, nunca foi a expressão do ideal corporativista de representação orgânica da nação, pois nunca deixou de ser um órgão auxiliar e consultivo do Governo e da Assembleia Nacional (SERAPIGLIA, 2011, p. 21-29).

O próprio nacional-sindicalismo - versão portuguesa do nazifascismo -, surgido em Portugal no começo dos anos trinta, embora incluísse movimentos de ideologia corporativista, nacionalista e antiliberal que tinham em comum a recusa da luta de classes, apelou a uma "revolução corporativa" que se exprimiu contra o corporativismo em curso, supostamente tímido. A concretizar-se, a revolução corporativa desejada pelos nacionais-sindicalistas seria devastadora para as instituições herdadas do Estado liberal; não permitiria qualquer compromisso entre o "Estado corporativo" e as anteriores formas de organização política e social, como sucedeu no salazarismo. Também por isso, Salazar e o seu círculo político preferiram usar a expressão "revolução nacional" ou, quando muito, chamar-lhe "revolução nacional corporativa", programa que na utopia reacionária dos corporativistas significava integrar a nação (a "nação orgânica" ou a constituição natural da sociedade) no Estado.

Embora esse organicismo de raiz tomista reelaborado pelos sociólogos de Oitocentos não fosse impossível de conjugar com o reformismo republicano (assim o fizeram Teófilo Braga e Manuel Emídio Garcia, por exemplo) e socializante (evidente em obras de Oliveira Martins e do próprio Marnoco e Sousa), acabou por vingar a versão católica-social doutrinada pelo Papa Leão XIII.

Os afluentes doutrinários do corporativismo português que o Estado Novo acolheu e instituiu foram, além desse "corporativismo das encíclicas", o conservadorismo contra-revolucionário e estrangeirado de Barrés e Maurras, o movimento integralista português e, sobretudo, já nos anos vinte, o arquétipo corporativista de Estado do fascismo italiano, isto, é, o corporativismo feito regime.

Fora deste espectro, poucas novidades. Como notou Fernando Rosas, o movimento nacional-sindicalista "fez o discurso corporativista 
das velhas direitas, ainda que emprestando-lhe, como em todo o lado, tons obreiristas, antiplutocráticos e milicianos" (ROSAS, 2012, p. 284) que as elites conservadoras receberam com frieza.

Sobrava a direita republicana, que encarou o corporativismo de maneira pragmática, "expediente prático e eficaz para repor a ordem nas finanças públicas, no Governo, nas empresas e nos negócios" (ROSAS, 2012, p. 284). E a direita tecnocrática, que o viu do mesmo modo, mas também como instrumento de regulação da economia que poderia facilitar o ambicionado fomento. Não espanta que o corporativismo católico de ideologia nacional-organicista tenha reunido um oficioso consenso e tenha povoado os textos basilares do regime.

A ameaça de contágio revolucionário vinda da revolução bolchevista de 1917, alguns ensaios de corporativismo político e social, em especial as ditaduras ibéricas de Sidónio Pais (1917-1918) e de Primo de Rivera (1923-1930) e as sucessivas crises do capitalismo, abalos que se repetiram de 1890 a 1929, compuseram o ambiente favorável para sepultar o demoliberalismo e reprimir a ofensiva socialista e comunista.

Volvidos quarenta anos do fim da ditadura de Salazar e Caetano, o conhecimento histórico do Estado Novo persiste em colocar-nos a mesma trilogia de problemas que o animou nas décadas de oitenta e noventa do século XX: 1) As origens ideológicas e sociais do regime e os seus processos de implantação no âmbito da crise do Estado liberal; 2) A natureza política do Estado Novo no contexto histórico dos fascismos da Europa de entre-guerras; 3) A extraordinária longevidade da ditadura portuguesa e a sua resistência às transformações externas e internas; 4) A natureza e os ciclos das políticas de modernização e desenvolvimento econômico. Se tudo cabe neste leque de questões, não é menos verdade que a construção e o funcionamento do sistema corporativo português são temas que atravessam qualquer uma das problemáticas.

As incoerências entre a teoria e a prática, as contradições e desvios dos corporativismos históricos da Europa de entre-guerras, em geral, e do sistema corporativo português instituído pelo Estado Novo, em particular, têm sido identificadas por historiadores, sociólogos e politólogos.

No caso português, tais evidências contraditórias têm-se revelado reconfortantes para o entendimento do corporativismo enquanto sistema, mas pouco estimulantes para o estudo histórico da sua experiência concreta e do efeito decisivo que parece ter tido na longevidade do próprio Estado Novo. Nomeadamente, no que toca à ação regular e 
ao impacto estrutural da miríade de organismos corporativos e paracorporativos imposta às forças vivas da "nação" a partir de 1933 ou mesmo antes, ainda sem a moldura jurídica constitucional.

O império da ideologia e a obsessão historiográfica de apurar em que medida o dogma corporativista gerou um sistema político e de representação de interesses realmente corporativo - questão elíptica que a própria doutrina alimentou -, parecem inibir a análise dos usos econômicos da ideia corporativa e o estudo dos seus impactos sociais.

Para tanto, falta estudar a prática das instituições corporativistas - ou das principais, a título de amostra -, cartografar os sectores econômicos onde foram forçadas de modo vertical e horizontal e tipificar os seus impactos. As instituições corporativistas erigidas pelo Estado Novo português legaram-nos um imenso caudal de meta-fontes, nem sempre esclarecedoras do quotidiano das instituições, da sua prática social e política ou das circunstâncias do "corporativismo real". Do outro lado do "objeto" de estudo ficam as instituições políticas, econômicas e sociais criadas debaixo da doutrina corporativa - ou seja, o sistema e a organização, realidades que não coincidem de todo.

\section{Referências}

ADLER, Franklin Hugh. Italian Industrialists from Liberalism to Fascism. The Political Development of the Industrial Bourgeoisie, 1906-1934. New York: Cambridge University Press, 1995.

ALMODÔVAR, António; CARDOSO, José Luís. Corporatism and the Economic Role of Government. In: MEDEMA, Steven G.; BOETTKE, Peter (Eds.). The Role of Government in the History of Economic Thought. Durham-London: Duke University Press, 2005. p. 333-354.

AMARO, António Rafael. A primeira reforma político-administrativa do Estado Novo: a experiência fracassada da divisão do Continente em Províncias (1936-1959). In: GARRIDO, A.; COSTA, L. Freire; DUARTE, L. Miguel (Org.). Economia, Instituições e Império. Estudos em Homenagem a Joaquim Romero Magalhães. Coimbra: Almedina, 2012.

BASTIEN, Carlos; CARDOSO, José Luís. From homo economicus to homo corporativus: A neglected critique of neoclassical economics. The Journal of SocioEconomics, n. 36, p. 120-127, 2007.

BERNARDO, João. Labirintos do Fascismo. Na Encruzilhada da Ordem e da Revolta. Porto: Edições Afrontamento, 2003.

CAPDEVIELLE, Jacques. Modernité du Corporatisme. Paris: Presses de Sciences Po, 2001.

CATROGA, Fernando. A Geografia dos Afectos Pátrios. Coimbra: Almedina, 2014.

COTTA, Alain. Le Corporatisme, stade ultime du capitalisme. Paris: Fayard, 2008. 
CARDOSO, José Luís Cardoso; MENDONÇA, Pedro. Corporatism and Beyond: an assessment of recente literature. Lisboa: ICS, 2012.

CROUCH, Colin; STREECK, Wolfgang (Eds.). The Diversity of Democracy. Corporatism, Social Order and Political Conflict. Cheltenham: Edward Elgar, 2006.

DE MICHELIS, Giuseppe. La Corporation dans le Monde. Économie Dirigée Internationale. Paris: Les Éditions Denoel et Steele, 1935.

FERNANDES, António Júlio Castro. O Corporativismo Fascista. Lisboa: Editorial Império, 1938.

GAGLIARDI, Alessio. Il corporativismo fascista. Editori Laterza: Roma-Bari, 2010 .

GARRIDO, Álvaro. Cooperação e Solidariedade. Uma História da Economia Social. Lisboa: Tinta-da-China, 2016.

. O Estado Novo e a Campanha do Bacalhau. Lisboa: Círculo de Leitores/Temas \& Debates, 2010.

GENTILE, Emilio. Fascismo. Storia e Interpretazione. Bari: Laterza, 2015.

HALL, Peter; SOSKICE, David (Eds.). Varieties of Capitalism. The Institutional Foundations of Comparative Advantage. New York: Oxford University Press, 2003.

KAPLAN, Steven; MINARD, Philippe (Dir.). La France, malade du corporatisme? XVIIIe-XXe siècles. Paris: Éditions Belin, 2004.

LEHMBRUCH, Gerhard, Liberal corporatism and party government. In: SCMITTER, Philippe; LEHMBRUCH, Gerhard (Ed.) Trends Towards Corporatist Intermediation. London: Sage, 1979. p. 147-183.

LUCENA, Manuel de. Corporatisme au Portugal, 1933-1974. Essai sur la nature et l'ambiguité du régime salazariste. In: MUSIEDLAK Didier (Dir.). Les Expériences Corporatives dans L'Aire Latine. Berne: Peter Lang, 2010. p. 153-202.

. A evolução do sistema corporativo português. Lisboa: Perspectivas \& Realidades, 1976. 2 v.

A herança de duas revoluções: continuidade e rupturas no Portugal postsalazarista. In: COELHO, Mário Baptista (Coord.). Portugal, O Sistema Político e Constitucional, 1974-1987. Lisboa: Instituto de Ciências Sociais, 1989. p. 505-555.

MADUREIRA, Nuno Luís. A Economia dos Interesses. Portugal entre as Guerras. Lisboa: Livros Horizonte, 2002.

MANOILESCO, Mihail. Le siécle du corporatisme: doctrine du corporatisme intégral et pur. Paris: Félix Alcan, 1934.

MILZA, Pierre. Les Fascismes. Paris: Éditions du Seuil, 2001.

MORNATI, Fiorenzo. "Le corporatisme italien vu par les économistes français des années trente". In: DOCKÈS, Pierre et all (Dir.). Les traditions économiques françaises, 1848-1939. Paris: CNRS Éditions, 2009. p. 728-729.

MOREIRA, Vital. Auto-Regulação Profissional e Administração Pública. Porto, Livraria Almedina, 1997.

OFFERLÉ, Michel. Sociologie des groupes d'intérêt, 2. ed. Paris: Montchrestien, 1998.

PAYNE, Stanley. A History of Fascism. Madison: The University of Wisconsin Press, 1996. 
PEREIRA, Pedro Teotónio. A Batalha do Futuro. Organização Corporativa. Lisboa: Livraria Clássica Editora, 1937. 2. ed.

PERROUX, François. Capitalisme et communauté de travail. Paris: Librairie du Receuil Sirey, 1938.

PINTO, António Costa. O corporativismo nas ditaduras da época do fascismo. Varia História, Belo Horizonte, v. 30, n. 52, jan.-abr. 2014.

ROSAS, Fernando. Salazar e o Poder. A Arte de Saber Durar. Lisboa: Tinta-da-China, 2012.

ROSAS, Fernando; GARRIDO, Álvaro (Coord.). Corporativismo, Fascismos, Estado Novo. Coimbra: Almedina, 2012.

SANTOMASSIMO, Gianpasquale. La terza via fascista. Il mito del corporativismo. Roma: Carocci, 2006.

SCHMITTER, Philippe. Portugal: do Autoritarismo à Democracia. Lisboa: Imprensa de Ciências Sociais, 1999.

. Still the century of corporatism? The Review of Politics, v, 36, p. 85-131, 1974.

SERAPIGLIA, Daniele. La via portoghese al corporativismo. Bologna: Carocci, 2011.

TONIOLO, Gianni. L'Economia dell'italia fascista. Bari: Editori Laterza, 1980.

TORGAL, Luís Reis. Estados Novos Estado Novo. Coimbra: Imprensa da Universidade, 2009. $2 \mathrm{v}$.

WIARDA, Howard. Corporatism and development: the Portuguese experience. Amherst: The University of Massachussets, 1977.

. O corporativismo em Portugal e no mundo moderno. In: GASPAR, Carlos; PATRIARCA, Fátima; MATOS, Luís Salgado de (Org.). Estado, Regimes e Revoluções. Estudos em homenagem a Manuel de Lucena. Lisboa: Imprensa de Ciências Sociais, 2012. p. 263-276.

WILliaMSON, Peter J. Corporatism in Perspective. An Introductory Guide to Corporatist Theory. London: Sage Publications, 1989.

Recebido: 22 de novembro de 2015 Aprovado: 11 de janeiro de 2016

\footnotetext{
Autor/Author:

ÁlVARO GARRIDO < agarrido@fe.uc.pt>

- Professor com agregação na Faculdade de Economia da Universidade de Coimbra, onde coordena o grupo de História Econômica e Social e a Escola de Estudos Avançados, e investigador do CEIS20. O seu trabalho incide na História econômica e das instituições e na História marítima contemporânea. Os temas do corporativismo, da economia social e da economia marítima são centrais no seu projecto de investigação. Publicou diversos livros e artigos internacionais sobre história econômica de Portugal, as pescas no contexto do Estado Novo português e a natureza do corporativismo salazarista. Prepara dois livros para publicação em 2016: Cooperação e Solidariedade - Uma História da Economia Social (Tinta-da-China); Queremos uma Economia Nova! O corporativismo Salazarista (Temas \& Debates).

- Professor at the Faculty of Economics at the Universidade de Coimbra, where he coordinates the group of Economic and Social History and the School of Advanced Studies, being also researcher of the CEIS20. His work focuses on Economic History, History of Institutions and Contemporary Maritime History. The themes corporatism, social economy and maritime economy are central to his research project. He has published several international books and papers about Portuguese economic history, fishing in the context of the Portuguese Estado Novo and the nature of the salazarist corporatism. He also has two books in preparation to be published in 2016: Cooperação e Solidariedade - Uma História da Economia Social (Tinta-da-China); Queremos uma Economia Nova! O corporativismo Salazarista (Temas \& Debates).
} 